\title{
Comparing robot-assisted thoracic surgical lobectomy with conventional video-assisted thoracic surgical lobectomy and wedge resection: Results from a multihospital database (Premier)
}

\author{
Scott J. Swanson, MD, ${ }^{a}$ Daniel L. Miller, MD, ${ }^{b}$ Robert Joseph McKenna, Jr, MD, ${ }^{c}$ John Howington, MD, ${ }^{d}$ \\ M. Blair Marshall, MD, ${ }^{\mathrm{e}}$ Andrew C. Yoo, MD, ${ }^{\mathrm{f}}$ Matthew Moore, MHA, ${ }^{\mathrm{g}}$ Candace L. Gunnarsson, EdD,${ }^{\mathrm{h}}$ and \\ Bryan F. Meyers, MD
}

\begin{abstract}
Background: Video-assisted thoracic surgical (VATS) lobectomies and wedge resections result in less morbidity and shorter length of stay than resections via thoracotomy. The impact of robot-assisted thoracic surgical (RATS) lobectomy on clinical and economic outcomes has not been examined. This study compared hospital costs and clinical outcomes for VATS lobectomies and wedge resections versus RATS.

Methods: Using the Premier hospital database, patients aged $\geq 18$ years with a record of thoracoscopic lobectomy, segmental resection, or excision of a lesion or tissue from the lung between 2009 and 2011 were identified. Procedures using robotic technology were identified if 1 of 2 conditions were met: (1) a robotic International Classification of Diseases, Ninth Revision procedure code or (2) the text fields in the hospital record indicated that the robot was used. Using a propensity score and based on severity and comorbidities, certain demographics and hospital characteristics were matched. The association between VATS or RATS and adverse events, hospital costs, surgery time, and length of stay was examined.
\end{abstract}

Results: Of 15,502 patient records analyzed, $96 \%(n=14,837)$ were performed without robotic assistance. Using robotic assistance was associated with higher average hospital costs per patient. The average cost of inpatient procedures with RATS was $\$ 25,040.70$ versus $\$ 20,476.60$ for VATS $(P=.0001)$ for lobectomies and $\$ 19,592.40$ versus $\$ 16,600.10(P=.0001)$ for wedge resections, respectively. Inpatient operating times were longer for RATS lobectomy than VATS lobectomy (4.49 hours vs 4.23 hours; $P=.0959)$ and wedge resection (3.26 vs 2.86 hours; $P=.0003$ ). Length of stay was similar with no differences in adverse events.

Conclusions: RATS lobectomy and wedge resection seem to have higher hospital costs and longer operating times, without any differences in adverse events. (J Thorac Cardiovasc Surg 2014;147:929-37)

\footnotetext{
From the Division of Minimally Invasive Thoracic Surgery, ${ }^{a}$ Brigham and Women's Hospital, Dana-Farber Cancer Institute, Harvard Medical School, Boston, Mass; Division of Thoracic Surgery, ${ }^{b}$ Emory University Healthcare, Atlanta, Ga; Division of Thoracic Surgery, ${ }^{\mathrm{c}}$ Cedars Sinai Medical Center, Los Angeles, Calif; Division of Thoracic Surgery and Surgical Quality, ${ }^{\mathrm{d}}$ NorthShore University Health System, Evanston, Ill; Division of Thoracic Surgery, ${ }^{\mathrm{e}}$ Georgetown University Medical Center, Washington, DC; Ethicon Endo-Surgery, Inc a Johnson \& Johnson Company, ${ }^{\mathrm{f}}$ Cincinnati, Ohio; Healthcare Policy and Economics, ${ }^{\mathrm{g}}$ Ethicon Endo-Surgery, Cincinnati, Ohio; $S^{2}$ Statistical Solutions, Inc., ${ }^{\text {h }}$ Cincinnati, Ohio; and Division of Cardiothoracic Surgery, ${ }^{\mathrm{i}}$ Barnes-Jewish Hospital Plaza, Washington University in St. Louis, St. Louis, Mo.

Disclosures: John Howington reports consulting fees from Ethicon Endo-Surgery. M. Blair Marshall reports consulting fees from Thoracic Surgery Clinics, Clinical Key, and Ethicon. Andrew C. Yoo is a full-time employee of Ethicon Endo-Surgery and reports equity ownership in Johnson and Johnson. Matthew Moore was a full-time employee of Ethicon Endo-Surgery at the time this research was completed. Candace L. Gunnarsson reports consulting fees from Ethicon Endo-Surgery. Bryan F. Meyers reports consulting fees from Ethicon Endo-Surgery and lecture fees from Varian. All other authors have nothing to disclose with regard to commercial support.

Matthew Moore is currently employed by Edwards Lifesciences.

Received for publication May 17, 2013; revisions received Aug 27, 2013; accepted for publication Sept 19, 2013; available ahead of print Nov 11, 2013.

Address for reprints: Candace L. Gunnarsson, 11176 Main St, Cincinnati, OH 45241

(E-mail: candaceg@s2stats.com).

$0022-5223 / \$ 36.00$

Copyright (c) 2014 by The American Association for Thoracic Surgery

http://dx.doi.org/10.1016/j.jtcvs.2013.09.046
}

Lung surgery for the purpose of diagnosis or treatment has evolved in the past 2 decades. Historically, surgery involving the lung was accomplished using 1 of 2 main approaches, depending on the clinical indication: via a thoracoscope inserted using a small incision or by an open thoracotomy, involving a larger incision and rib spreading to improve visibility and access for control of the surgical anatomy.

Thoracoscopic procedures have been transformed by the ongoing refinement of video-assisted thoracoscopic surgery (VATS) techniques and equipment, particularly high-definition cameras and monitors. For traditional thoracotomy indications, VATS is an evolving technique and is increasingly applied in situations where traditional open thoracotomy has long been used. There is a small but increasing literature to support the growth of VATS in this context. However, VATS is still an evolving phenomenon, with a developing research base,${ }^{1-4}$ and with a variable definition. ${ }^{3-5}$ Variations exist in the number of port incisions and the appropriate incision length.

The purported benefits of VATS in lung surgery compared with open thoracotomy in the literature 


\section{Abbreviations and Acronyms \\ APR- = All Patient Refined Diagnosis Related \\ DRG Groups \\ ICD-9 = International Classification of Diseases, Ninth Edition \\ RATS $=$ robot-assisted thoracic surgical \\ SD $=$ standard deviation \\ VATS $=$ video-assisted thoracic surgical}

published to date includes smaller incisions, less pain, less blood loss, less respiratory compromise, less complications, and faster recovery times, all translating into shorter length of stay and similar survival. ${ }^{6}$ These findings have been reported in systematic reviews of randomized and nonrandomized clinical trials, ${ }^{7}$ and in comparative studies. ${ }^{2}$ In a comparative study of patients with lung cancer, Cajipe and colleagues, ${ }^{8}$ found that there were fewer complications in VATS patients (14 of 46, 30\%) than their open counterparts ( 26 of $45,58 \% ; P=.009$ ). VATS patients also had a chest tube for a shorter time and shorter length of stay. In multivariate analysis, VATS was associated independently with a reduced risk of complications (odds ratio, 0.359; $P=.04$ ).

The impact of RATS on clinical and economic outcomes has not been examined, however. This study compared hospital costs and clinical outcomes for VATS lung resection versus RATS lung resection.

Despite several publications in support of robotic surgery, controversy still remains over limited highquality evidence of improved clinical outcomes compared with traditional minimally invasive approaches. Clinical outcomes suggest that robotic surgery is equivalent to conventional minimally invasive procedures when important end points such as conversion to open surgery, hospital stay, and recovery time are considered. ${ }^{9,10}$

The adoption and diffusion of this technology in thoracic surgery, coupled with limited high-quality evidence of improved outcomes compared with traditional VATS procedures, raises important questions about resource allocation. The systems typically cost between $\$ 1$ million and $\$ 2.5$ million $^{11}$ plus an additional expensive yearly service contract. Additional direct costs of roboticassisted surgery include instrument disposables and potentially increased procedure time.

In this era of comparative effectiveness and health care reform in the United States, and with concerns about resource utilization at the forefront, the trend toward RATS deserves further evaluation. Therefore, this study examined the clinical and economic outcomes (cost and utilization) in patients undergoing VATS lung resection versus RATS lung resection.

\section{MATERIALS AND METHODS \\ Data Source}

The Premier hospital database was used as the data source for this study. ${ }^{12}$ This database contains complete data on patient billing, hospital costs, and coding histories from more than 600 health care facilities throughout the United States. The data for this study were extracted from more than 25 million inpatient discharges and 175 million hospital outpatient visits from acute care facilities, ambulatory surgery centers, and clinics across the nation.

A protocol describing the analysis objectives, criteria for patient selection, data elements of interest, and statistical methods was submitted to the New England Institutional Review Board (NEIRB) and exemption was obtained.

Eligible patients were $\geq 8$ years of age and had undergone a VATS lobectomy or wedge resection between 2009 and 2011, for which the lobectomy or wedge resection was the primary reason for surgery. Patients were categorized according to the following types of VATS procedure: lobectomy (code 32.41), wedge resection (code 32.30 or 32.20).

Lobectomy and wedge resection procedures using robotic technology were identified if 1 of the 2 following conditions were met: (1) a robotic International Classification of Diseases, Ninth Edition (ICD-9) procedure code accompanied the primary procedure code of interest or (2) text fields were found when mining the hospital charge master file for each patient indicating use of the robot. Procedures that involved conversion from minimally invasive to open or between robotic and VATS approaches were excluded from the analysis dataset.

For all eligible patients, elements describing hospital cost, surgery time, length of stay, use of robot, type of thoracic procedure, and indication for procedure were obtained from the data. Cost analysis (calculation) reflected the cost of the robotic procedure to the hospital but did not include acquisition or the annual maintenance fee for the da Vinci robot (Intuitive Surgical, Inc, Sunnyvale, Calif). The preoperative All Patient Refined Diagnosis Related Groups (APR-DRG) severity level was used as an index of comorbidity. The 3M APR-DRG Classification System is a widely adopted proprietary risk adjustment classification tool that uses information from routine claims data to produce valid and reliable severity measurement and risk adjustment scores. ${ }^{13}$ It is used to account for differences related to an individual's severity of illness or risk of mortality in large datasets. Comorbid conditions that might influence procedure selection or outcomes of interest, such as the presence of cardiovascular or pulmonary disease, cancer, or diabetes mellitus, were obtained using ICD-9 diagnosis codes. Appendix Table 1 provides a detailed list of all ICD-9 codes for each condition included in the study. Information on sociodemographic characteristics and health insurance status was also included, as were descriptors of the care setting, namely census region, urban or rural setting, teaching hospital status, and facility bed count.

TABLE 1. Attrition

\begin{tabular}{|c|c|c|}
\hline Description & $\begin{array}{l}\text { Number of } \\
\text { patients } \\
\text { remaining }\end{array}$ & $\begin{array}{c}\text { Number of } \\
\text { patients } \\
\text { dropped } \\
\text { for this reason }\end{array}$ \\
\hline $\begin{array}{l}\text { Total number of patients in } \\
\text { Premier database } 2009 \\
\text { Q1 to } 2011 \text { Q2 }\end{array}$ & $102,914,774$ & \\
\hline $\begin{array}{l}\text { Patients with a primary } \\
\text { procedure code for } \\
\text { lobectomy or wedge } \\
\text { resection }(32.20,32.30,32.41)\end{array}$ & 15,965 & $102,898,809$ \\
\hline $\begin{array}{l}\text { Patients } 18 \text { y or older at date of } \\
\text { procedure }\end{array}$ & 15,596 & 369 \\
\hline Patients with inpatient visits only & 15,502 & 94 \\
\hline
\end{tabular}


TABLE 2. Patient demographics-before match

\begin{tabular}{|c|c|c|c|c|c|c|c|c|c|c|}
\hline \multirow[b]{3}{*}{ Category } & \multicolumn{5}{|c|}{ Lobectomy } & \multicolumn{5}{|c|}{ Wedge resection } \\
\hline & \multicolumn{2}{|c|}{ RATS } & \multicolumn{2}{|c|}{ VATS } & \multirow[b]{2}{*}{$P$ value } & \multicolumn{2}{|c|}{ RATS } & \multicolumn{2}{|c|}{ VATS } & \multirow[b]{2}{*}{$P$ value } \\
\hline & $\mathbf{N}$ & Percent & $\mathbf{N}$ & Percent & & $\mathbf{N}$ & Percent & $\mathbf{N}$ & Percent & \\
\hline Total number & 335 & 100 & 3818 & 100 & & 330 & 100 & 11,019 & 100 & \\
\hline Age (mean) & 66.36 & & 66.27 & & .8856 & 61.81 & & 59.56 & & .0126 \\
\hline Age group & & & & & .9089 & & & & & .1606 \\
\hline $18-40 y$ & 7 & 2.09 & 83 & 2.17 & & 32 & 9.7 & 1443 & 13.1 & \\
\hline $41-50 y$ & 25 & 7.46 & 243 & 6.36 & & 28 & 8.48 & 1302 & 11.82 & \\
\hline $51-60 y$ & 60 & 17.91 & 738 & 19.33 & & 75 & 22.73 & 2263 & 20.54 & \\
\hline $61-70 y$ & 109 & 32.54 & 1288 & 33.73 & & 98 & 29.7 & 2959 & 26.85 & \\
\hline $71-80 y$ & 102 & 30.45 & 1145 & 29.99 & & 75 & 22.73 & 2359 & 21.41 & \\
\hline$>80 \mathrm{y}$ & 32 & 9.55 & 321 & 8.41 & & 22 & 6.67 & 693 & 6.29 & \\
\hline Gender & & & & & .4484 & & & & & .7783 \\
\hline Female & 176 & 52.54 & 2088 & 54.69 & & 169 & 51.21 & 5451 & 49.47 & \\
\hline Male & 159 & 47.46 & 1730 & 45.31 & & 161 & 48.79 & 5564 & 50.49 & \\
\hline Unknown & 0 & 0 & 0 & 0 & & 0 & 0 & 4 & 0.04 & \\
\hline Insurance & & & & & $<.0001$ & & & & & .7399 \\
\hline Government & 195 & 58.21 & 2490 & 65.22 & & 186 & 56.36 & 5973 & 54.21 & \\
\hline Managed care & 124 & 37.01 & 977 & 25.59 & & 103 & 31.21 & 3617 & 32.83 & \\
\hline Other & 16 & 4.78 & 351 & 9.19 & & 41 & 12.42 & 1429 & 12.97 & \\
\hline Race & & & & & $<.0001$ & & & & & .0011 \\
\hline White & 240 & 71.64 & 3012 & 78.89 & & 264 & 80 & 8021 & 72.79 & \\
\hline African American & 14 & 4.18 & 327 & 8.56 & & 21 & 6.36 & 1045 & 9.48 & \\
\hline Hispanic & 40 & 11.94 & 60 & 1.57 & & 16 & 4.85 & 345 & 3.13 & \\
\hline Other & 41 & 12.24 & 419 & 10.97 & & 29 & 8.79 & 1608 & 14.59 & \\
\hline Health status* & & & & & .1353 & & & & & .001 \\
\hline APR-DRG severity level $(1,2)$ & 267 & 79.7 & 2905 & 76.09 & & 273 & 82.73 & 8236 & 74.74 & \\
\hline APR-DRG severity level $(3,4)$ & 68 & 20.3 & 913 & 23.91 & & 57 & 17.27 & 2783 & 25.26 & \\
\hline Malignancy indication & & & & & .0093 & & & & & .0006 \\
\hline No lung cancer & 48 & 14.33 & 376 & 9.85 & & 168 & 50.91 & 6761 & 61.36 & \\
\hline Primary neoplasm of the lung & 266 & 79.4 & 3268 & 85.59 & & 116 & 35.15 & 3064 & 27.81 & \\
\hline Metastases other than lung & 21 & 6.27 & 174 & 4.56 & & 46 & 13.94 & 1194 & 10.84 & \\
\hline \multicolumn{11}{|l|}{ Comorbid conditions } \\
\hline Myocardial infarction, acute or old & 30 & 8.96 & 358 & 9.38 & .7994 & 30 & 9.09 & 825 & 7.49 & .2767 \\
\hline Congestive heart failure & 22 & 6.57 & 235 & 6.16 & .7641 & 24 & 7.27 & 900 & 8.17 & .5580 \\
\hline Chronic or unspecified heart failure & 6 & 1.79 & 58 & 1.52 & .6985 & 3 & 0.91 & 287 & 2.6 & .0544 \\
\hline Peripheral vascular disease & 30 & 8.96 & 396 & 10.37 & .4125 & 25 & 7.58 & 798 & 7.24 & .8178 \\
\hline Dementia & 9 & 2.69 & 54 & 1.41 & .0678 & 5 & 1.52 & 139 & 1.26 & 6849 \\
\hline Chronic pulmonary disease & 171 & 51.04 & 1917 & 50.21 & .7694 & 163 & 49.39 & 5649 & 51.27 & .5026 \\
\hline Connective tissue disease & 8 & 2.39 & 149 & 3.9 & .1634 & 18 & 5.45 & 549 & 4.98 & 6980 \\
\hline Liver disease & 18 & 5.37 & 184 & 4.82 & .6514 & 23 & 6.97 & 647 & 5.87 & .4043 \\
\hline Chronic viral hepatitis & 0 & 0 & 33 & 0.86 & .0876 & 5 & 1.52 & 113 & 1.03 & .3876 \\
\hline Renal insufficiency, chronic & 22 & 6.57 & 270 & 7.07 & .7291 & 18 & 5.45 & 801 & 7.27 & .2094 \\
\hline Diabetes mellitus & 82 & 24.48 & 770 & 20.17 & .0611 & 51 & 15.45 & 2161 & 19.61 & .0603 \\
\hline
\end{tabular}

$R A T S$, Robot-assisted thoracic surgery; VATS, video-assisted thoracic surgery; $A P R-D R G$, all patient refined diagnosis related group. *APR-DRG severity level was used as an index of preoperative comorbidity.

Adverse events (identified by ICD-9 codes) that occurred intraoperatively and within 30 days postoperatively that included pulmonary complications were flagged and included in the analysis. These were further grouped as major or minor complications for analysis. A detailed list of each event and the corresponding ICD-9 code is found in Appendix Table 2.

\section{Statistical Analysis}

The study objective was to use the Premier hospital database to compare clinical and economic outcomes in patients undergoing lobectomy or wedge resection using VATS versus RATS. Outcomes of interest included adverse events (minor and major), hospital costs, length of stay, and surgery time. Costs were the actual costs incurred by the hospital for all treatments and services related to the lobectomy and wedge resection and did not include robotic capital or service contracts.

A quasi-randomization method called propensity scoring was used to create groups of analyzable patients who were well matched. Propensity scores were assigned based on likely predictors of the outcome of interest. Covariates on which to match were selected based on their availability in the Premier database, as well as their general acceptance as factors associated with the outcomes of interest. The goal of this propensity-matching 
TABLE 3. Hospital demographics based on patient counts

\begin{tabular}{|c|c|c|c|c|c|c|c|c|c|c|}
\hline \multirow[b]{3}{*}{ Category } & \multicolumn{5}{|c|}{ Lobectomy } & \multicolumn{5}{|c|}{ Wedge resection } \\
\hline & \multicolumn{2}{|c|}{ RATS } & \multicolumn{2}{|c|}{ VATS } & \multirow[b]{2}{*}{$P$ value } & \multicolumn{2}{|c|}{ RATS } & \multicolumn{2}{|c|}{ VATS } & \multirow[b]{2}{*}{$P$ valu } \\
\hline & $\mathbf{N}$ & Percent & $\mathbf{N}$ & Percent & & $\mathbf{N}$ & Percent & $\mathbf{N}$ & Percent & \\
\hline Total number & 335 & 100 & 3818 & 100 & & 330 & 100 & 11,019 & 100 & \\
\hline Census region & & & & & $<.0001$ & & & & & $<.0001$ \\
\hline Northeast & 52 & 15.52 & 908 & 23.78 & & 77 & 23.33 & 2858 & 25.94 & \\
\hline West & 0 & 0 & 603 & 15.79 & & 22 & 6.67 & 1755 & 15.93 & \\
\hline South & 253 & 75.52 & 1693 & 44.34 & & 200 & 60.61 & 4160 & 37.75 & \\
\hline Midwest & 30 & 8.96 & 614 & 16.08 & & 31 & 9.39 & 2246 & 20.38 & \\
\hline Location & & & & & .1851 & & & & & .0539 \\
\hline Urban & 315 & 94.03 & 3650 & 95.6 & & 319 & 96.67 & 10,375 & 94.16 & \\
\hline Not urban & 20 & 5.97 & 168 & 4.4 & & 11 & 3.33 & 644 & 5.84 & \\
\hline Type & & & & & $<.0001$ & & & & & $<.0001$ \\
\hline Teaching & 292 & 87.16 & 2132 & 55.84 & & 281 & 85.15 & 5744 & 52.13 & \\
\hline Nonteaching & 43 & 12.84 & 1686 & 44.16 & & 49 & 14.85 & 5275 & 47.87 & \\
\hline Bed count & & & & & .0023 & & & & & .0585 \\
\hline$<50$ & 0 & 0 & 0 & 0 & & 0 & 0 & 7 & 0.06 & \\
\hline $51-100$ & 0 & 0 & 15 & 0.39 & & 0 & 0 & 40 & 0.36 & \\
\hline $101-200$ & 1 & 0.3 & 141 & 3.69 & & 6 & 1.82 & 515 & 4.67 & \\
\hline$>200$ & 334 & 99.7 & 3662 & 95.91 & & 324 & 98.18 & 10,457 & 94.9 & \\
\hline
\end{tabular}

RATS, Robot-assisted thoracic surgery; VATS, video-assisted thoracic surgery.

analysis was to find pairs of patients receiving lobectomy or wedge resection via RATS or VATS procedures, who shared like propensities based on the matching variables. An SAS macro from the Mayo Clinic used nearestneighbor matching on the estimated propensity scores to choose matches for the patients who had a RATS procedure. ${ }^{14}$ Propensity scores were calculated for receipt of robotic procedures for each patient included in the analysis based on a nonparsimonious multivariable logistic regression model. Patients were matched on the following characteristics: severity group, age, gender, race, region, size of facility, teaching facility (yes/ no), location of facility, insurance group, malignancy status, chronic pulmonary disease, chronic viral hepatitis, connective tissue disease, congestive heart failure, diabetes mellitus, liver disease, myocardial infarction, acute or old, other chronic or unspecified heart failure, peripheral vascular disease, and chronic renal insufficiency. The robotic and nonrobotic patients were randomly ordered and a nonrobotic patient with a propensity score closest to the first robotic patient was chosen. Assessment of residual bias was conducted by evaluating the differences in the distribution of patient characteristics before and after matching.

To assess the extent to which the propensity matching reduced confounders, the distribution of several variables before and after matching were compared, including age, gender, race, insurance type, health status, malignancy indication, region, location, facility type, facility size, and comorbid conditions among the patients in the cohorts. Group comparisons were made using $\chi^{2}$ tests. Least square means were used to test for differences between the matched cohorts on the 3 continuous variables of interest: hospital cost, surgery time, and length of stay. Logistic regression models were used to test for significant differences between the 2 groups and to generate odds ratios on the following categories of adverse events/complications: major and minor. To further assess any residual bias that may occur because only a few hospitals represent most of the robotic procedures in the sample, sensitivity analysis was conducted by running multiple regression models on 1 of the hospitals in which most of the robotic procedures were performed and a nonrobotic hospital meeting the same hospital characteristics. Ordinary least squares regression models were run for hospital costs and logistic regression models were run for adverse events, both major and minor. Analyses were performed using SAS Version 9.2 (SAS Institute Inc., Cary, NC).

\section{RESULTS}

A total of 15,502 patient records from 305 hospitals were analyzed. The patient attrition process is shown in Table 1 . Ninety-six percent of these thoracic procedures were traditional VATS $(n=14,837)$; lung resection was performed with RATS in 665 procedures, $4 \%$ of the total. In the robotic group, 335 lobectomies and 330 wedge resections were performed.

Before matching, patients undergoing RATS lobectomy had similar distributions for age, gender, and health status. Those undergoing RATS resection had similar distributions for age, gender, and insurance type compared with those undergoing VATS lung resection (Table 2). Furthermore, few differences in comorbidities were noted between robot and nonrobot groups. Characteristics of the hospitals showed notable differences for region, teaching versus nonteaching, and bed count. For teaching versus nonteaching and bed count, most of the robotic procedures were performed in teaching hospitals (292 of 335 lobectomies, 281 of 330 wedge resections) with more than 200 beds ( 334 of 335 lobectomies, 324 of 330 wedge resections), compared with nonrobotic procedures, with almost half coming from nonteaching hospitals ( $44 \%$ lobectomy, $48 \%$ wedge resection) with greater variation in bed size (Table 3 ).

To balance cohorts and mitigate the possibility of confounders and the large discrepancy in sample size between robotic and nonrobotic procedures, patients were matched using a propensity score, as described earlier, on certain demographic and hospital characteristics. After matching, a total of 1240 patients remained; 590 lobectomies and 650 wedge resections in each group 
TABLE 4. Patient demographics-matched cohorts

\begin{tabular}{|c|c|c|c|c|c|c|c|c|c|c|}
\hline \multirow[b]{3}{*}{ Category } & \multicolumn{5}{|c|}{ Lobectomy } & \multicolumn{5}{|c|}{ Wedge resection } \\
\hline & \multicolumn{2}{|c|}{ RATS } & \multicolumn{2}{|c|}{ VATS } & \multirow[b]{2}{*}{$P$ value } & \multicolumn{2}{|c|}{ RATS } & \multicolumn{2}{|c|}{ VATS } & \multirow[b]{2}{*}{$P$ value } \\
\hline & $\mathbf{N}$ & Percent & $\mathbf{N}$ & Percent & & $\mathbf{N}$ & Percent & $\mathbf{N}$ & Percent & \\
\hline Total number & 295 & 100 & 295 & 100 & & 325 & 100 & 325 & 100 & \\
\hline Age (mean) & 66.43 & & 66.54 & & .9112 & 61.74 & & 61.50 & & .8403 \\
\hline Age group & & & & & .9596 & & & & & .9307 \\
\hline $18-40 y$ & 7 & 2.37 & 5 & 1.69 & & 32 & 9.85 & 34 & 10.46 & \\
\hline $41-50 \mathrm{y}$ & 21 & 7.12 & 18 & 6.1 & & 28 & 8.62 & 32 & 9.85 & \\
\hline $51-60$ y & 51 & 17.29 & 58 & 19.66 & & 74 & 22.77 & 63 & 19.38 & \\
\hline $61-70$ y & 99 & 33.56 & 98 & 33.22 & & 95 & 29.23 & 98 & 30.15 & \\
\hline $71-80 y$ & 88 & 29.83 & 88 & 29.83 & & 75 & 23.08 & 78 & 24 & \\
\hline$>80 \mathrm{y}$ & 29 & 9.83 & 28 & 9.49 & & 21 & 6.46 & 20 & 6.15 & \\
\hline Gender & & & & & .4574 & & & & & .0698 \\
\hline Female & 154 & 52.2 & 163 & 55.25 & & 167 & 51.38 & 190 & 58.46 & \\
\hline Male & 141 & 47.8 & 132 & 44.75 & & 158 & 48.62 & 135 & 41.54 & \\
\hline Unknown & & & & & & & & & & \\
\hline Insurance & & & & & .6862 & & & & & .7658 \\
\hline Government & 173 & 58.64 & 180 & 61.02 & & 183 & 56.31 & 174 & 53.54 & \\
\hline Managed care & 106 & 35.93 & 103 & 34.92 & & 101 & 31.08 & 106 & 32.62 & \\
\hline Other & 16 & 5.42 & 12 & 4.07 & & 41 & 12.62 & 45 & 13.85 & \\
\hline Race & & & & & .4626 & & & & & .9712 \\
\hline White & 235 & 79.66 & 249 & 84.41 & & 264 & 81.23 & 264 & 81.23 & \\
\hline African American & 14 & 4.75 & 11 & 3.73 & & 21 & 6.46 & 21 & 6.46 & \\
\hline Hispanic & 7 & 2.37 & 7 & 2.37 & & 11 & 3.38 & 13 & 4 & \\
\hline Other & 39 & 13.22 & 28 & 9.49 & & 29 & 8.92 & 27 & 8.31 & \\
\hline Health status* & & & & & .7597 & & & & & .1921 \\
\hline APR-DRG severity level $(1,2)$ & 233 & 78.98 & 236 & 80 & & 269 & 82.77 & 281 & 86.46 & \\
\hline APR-DRG severity level $(3,4)$ & 62 & 21.02 & 59 & 20 & & 56 & 17.23 & 44 & 13.54 & \\
\hline Malignancy indication & & & & & .9706 & & & & & .5428 \\
\hline No lung cancer & 40 & 13.56 & 38 & 12.88 & & 167 & 51.38 & 169 & 52 & \\
\hline Primary neoplasm of the lung & 238 & 80.68 & 240 & 81.36 & & 113 & 34.77 & 120 & 36.92 & \\
\hline Metastases other than lung & 17 & 5.76 & 17 & 5.76 & & 45 & 13.85 & 36 & 11.08 & \\
\hline Census region & & & & & $<.0001$ & & & & & .9672 \\
\hline Northeast & 50 & 16.95 & 94 & 31.86 & & 77 & 23.69 & 82 & 25.23 & \\
\hline West & 0 & 0 & 23 & 7.8 & & 22 & 6.77 & 23 & 7.08 & \\
\hline South & 215 & 72.88 & 123 & 41.69 & & 195 & 60 & 190 & 58.46 & \\
\hline Midwest & 30 & 10.17 & 55 & 18.64 & & 31 & 9.54 & 30 & 9.23 & \\
\hline Location & & & & & .4915 & & & & & .2464 \\
\hline Urban & 275 & 93.22 & 279 & 94.58 & & 314 & 96.62 & 308 & 94.77 & \\
\hline Not urban & 20 & 6.78 & 16 & 5.42 & & 11 & 3.38 & 17 & 5.23 & \\
\hline Type & & & & & .3974 & & & & & 1.0000 \\
\hline Teaching & 252 & 85.42 & 259 & 87.8 & & 276 & 84.92 & 276 & 84.92 & \\
\hline Nonteaching & 43 & 14.58 & 36 & 12.2 & & 49 & 15.08 & 49 & 15.08 & \\
\hline Bed count & & & & & .5627 & & & & & .0117 \\
\hline$<50$ & 0 & 0 & 0 & 0 & & & & & & \\
\hline $51-100$ & 0 & 0 & 0 & 0 & & 0 & 0 & 1 & 0.31 & \\
\hline $101-200$ & 1 & 0.34 & 2 & 0.68 & & 6 & 1.85 & 20 & 6.15 & \\
\hline$>200$ & 294 & 99.66 & 293 & 99.32 & & 319 & 98.15 & 304 & 93.54 & \\
\hline \multicolumn{11}{|l|}{ Comorbid conditions } \\
\hline Myocardial infarction, acute or old & 26 & 8.81 & 24 & 8.14 & .7675 & 29 & 8.92 & 28 & 8.62 & .8897 \\
\hline Congestive heart failure & 21 & 7.12 & 16 & 5.42 & .3959 & 22 & 6.77 & 20 & 6.15 & .7497 \\
\hline Chronic or unspecified heart failure & 6 & 2.03 & 8 & 2.71 & .5885 & 3 & 0.92 & 3 & 0.92 & 1.0000 \\
\hline Peripheral vascular disease & 25 & 8.47 & 27 & 9.15 & .7715 & 25 & 7.69 & 24 & 7.38 & .8819 \\
\hline Dementia & 8 & 2.71 & 3 & 1.02 & .1281 & 5 & 1.54 & 3 & 0.92 & .4768 \\
\hline Chronic pulmonary disease & 148 & 50.17 & 153 & 51.86 & .6805 & 161 & 49.54 & 165 & 50.77 & .7537 \\
\hline
\end{tabular}




\begin{tabular}{|c|c|c|c|c|c|c|c|c|c|c|}
\hline \multirow[b]{3}{*}{ Category } & \multicolumn{5}{|c|}{ Lobectomy } & \multicolumn{5}{|c|}{ Wedge resection } \\
\hline & \multicolumn{2}{|c|}{ RATS } & \multicolumn{2}{|c|}{ VATS } & \multirow[b]{2}{*}{$P$ value } & \multicolumn{2}{|c|}{ RATS } & \multicolumn{2}{|c|}{ VATS } & \multirow[b]{2}{*}{$P$ value } \\
\hline & $\mathbf{N}$ & Percent & $\mathbf{N}$ & Percent & & $\mathbf{N}$ & Percent & $\mathbf{N}$ & Percent & \\
\hline Connective tissue disease & 8 & 2.71 & 8 & 2.71 & 1.0000 & 18 & 5.54 & 17 & 5.23 & .8620 \\
\hline Liver disease & 16 & 5.42 & 9 & 3.05 & .1525 & 22 & 6.77 & 15 & 4.62 & .2360 \\
\hline Chronic viral hepatitis & 0 & 0 & 2 & 0.68 & .1566 & 5 & 1.54 & 3 & 0.92 & .4768 \\
\hline Renal insufficiency, chronic & 21 & 7.12 & 10 & 3.39 & .0424 & 18 & 5.54 & 17 & 5.23 & .8620 \\
\hline Diabetes mellitus & 68 & 23.05 & 60 & 20.34 & .4242 & 50 & 15.38 & 52 & 16 & .8292 \\
\hline
\end{tabular}

RATS, Robot-assisted thoracic surgery; VATS, video-assisted thoracic surgery; APR-DRG, all patient refined diagnosis related group. *APR-DRG severity level was used as an index of preoperative comorbidity.

from 132 hospitals; of these, there were 40 hospitals (30\%) where robotic procedures were being performed. Patient characteristics, comorbid conditions, and hospital characteristics after matching are represented in Table 4. After matching, patients were balanced with respect to demographics, comorbid conditions, and hospital characteristics, with the exception of region for the lobectomy cohort and bed count for the wedge resection cohort.

After matching, cohorts were tested for differences in average hospital costs, operating room time, and length of stay (Table 5). The average cost of inpatient procedures with/without robotic assistance was $\$ 25,040.70$ versus $\$ 20,476.58(P=.0001)$ for lobectomies and $\$ 19,592.42$ versus $\$ 16,600.13(P=.0001)$ for wedge resections, respectively. Operating room times were longer, although not statistically different for robotic lobectomy (4.49 vs 4.23 hours; $P=.0959$ ). Operating room times were increased for robotic wedge resection versus nonrobotic wedge resection ( 3.26 vs 2.86 hours; $P=.0003$ ). Average length of stay of both cohorts was not statistically different for lobectomy (6.07 vs 5.83 days; $P=.6131)$ and wedge resection (5.23 vs 5.38 days; $P=.7188$ ).

Adverse events occurring in the postoperative period, up to 30 days after discharge, were tabulated and grouped into major and minor. Complications rates between robotic and nonrobotic surgery cohorts, regardless of whether they were examined within a perioperative 30-day period or only within the original perioperative hospital stay (Table 6) were reported. The odds of an event occurring were not significantly different for major and minor events in either time period for lobectomy or wedge resection (Table 7).

\section{Sensitivity Analysis}

In the propensity model, the following hospital characteristics were adjusted: location (urban vs rural), region, teaching status, and bed size. However, more hospitals contributed to our sample of nonrobotic procedures than robotic procedures. Of the 132 hospitals in our sample, only 40 had robotic procedures. Therefore, to further assess any residual bias that may occur because only a few hospitals represented most of the robotic procedures in the sample, the 1 hospital in which 126 lobectomies and 71 wedge resections were performed was matched to a nonrobotic hospital meeting the same hospital characteristics: southern, urban, teaching with a bed count of 500. Only the patients from these 2 hospitals were analyzed. Results of the ordinary least squares cost model revealed significantly higher differences in costs for RATS lobectomy

TABLE 5. Length of stay, hospital costs, and surgery time after matching

\begin{tabular}{|c|c|c|c|c|c|c|}
\hline & \multicolumn{3}{|c|}{ Lobectomy } & \multicolumn{3}{|c|}{ Wedge resection } \\
\hline & RATS & VATS & $P$ value & RATS & VATS & $P$ value \\
\hline \multicolumn{7}{|c|}{ Length of stay (d) } \\
\hline Median & 4 & 4 & & 4 & 4 & \\
\hline Mean & 6.07 & 5.83 & 6131 & 5.23 & 5.38 & 0.7188 \\
\hline SD & 6.44 & 5.03 & & 5.18 & 5.27 & \\
\hline \multicolumn{7}{|c|}{ Total hospital costs $(\$)$} \\
\hline Median & $21,833.34$ & $18,080.11$ & & $17,341.33$ & $13,640.52$ & \\
\hline Mean & $25,040.70$ & $20,476.58$ & $<.0001$ & $19,592.42$ & $16,600.13$ & .0001 \\
\hline SD & $13,164.01$ & $10,977.67$ & & $9,293.64$ & $10,367.82$ & \\
\hline \multicolumn{7}{|c|}{ Operating room time $(\mathrm{h})$} \\
\hline Median & 4.25 & 4 & & 2.93 & 2.5 & \\
\hline Mean & 4.49 & 4.23 & .0959 & 3.26 & 2.86 & .0003 \\
\hline SD & 1.98 & 1.73 & & 1.41 & 1.31 & \\
\hline
\end{tabular}

RATS, Robot-assisted thoracic surgery; VATS, video-assisted thoracic surgery; $S D$, standard deviation. 
TABLE 6. Adverse events among matched data by analysis groups

\begin{tabular}{|c|c|c|c|c|c|c|c|c|c|c|c|c|c|c|c|c|}
\hline \multirow[b]{4}{*}{ Category } & \multicolumn{8}{|c|}{ Lobectomy } & \multicolumn{8}{|c|}{ Wedge resection } \\
\hline & \multicolumn{4}{|c|}{ RATS } & \multicolumn{4}{|c|}{ VATS } & \multicolumn{4}{|c|}{ RATS } & \multicolumn{4}{|c|}{ VATS } \\
\hline & \multicolumn{2}{|c|}{ During } & \multicolumn{2}{|c|}{ During or after } & \multicolumn{2}{|c|}{ During } & \multicolumn{2}{|c|}{ During or after } & \multicolumn{2}{|c|}{ During } & \multicolumn{2}{|c|}{ During or after } & \multicolumn{2}{|c|}{ During } & \multicolumn{2}{|c|}{ During or after } \\
\hline & $\mathbf{N}$ & Percent & $\mathbf{N}$ & Percent & $\mathbf{N}$ & Percent & $\mathbf{N}$ & Percent & $\mathbf{N}$ & Percent & $\mathbf{N}$ & Percent & $\mathbf{N}$ & Percent & $\mathbf{N}$ & Percent \\
\hline Total number & 295 & 100 & 295 & 100 & 295 & 100 & 295 & 100 & 325 & 100 & 325 & 100 & 325 & 100 & 325 & 100 \\
\hline Any major event & 40 & 13.56 & 50 & 16.95 & 50 & 16.95 & 56 & 18.98 & 53 & 16.31 & 71 & 21.85 & 41 & 12.62 & 51 & 15.69 \\
\hline Acute respiratory failure & 16 & 5.42 & 18 & 6.1 & 20 & 6.78 & 22 & 7.46 & 21 & 6.46 & 32 & 9.85 & 20 & 6.15 & 22 & 6.77 \\
\hline Empyema & 1 & 0.34 & 2 & 0.68 & 1 & 0.34 & 2 & 0.68 & 1 & 0.31 & 3 & 0.92 & 4 & 1.23 & 4 & 1.23 \\
\hline Bronchopleural fistula & 5 & 1.69 & 5 & 1.69 & 2 & 0.68 & 3 & 1.02 & 3 & 0.92 & 3 & 0.92 & 1 & 0.31 & 1 & 0.31 \\
\hline Pneumonia & 18 & 6.1 & 25 & 8.47 & 27 & 9.15 & 29 & 9.83 & 28 & 8.62 & 33 & 10.15 & 16 & 4.92 & 24 & 7.38 \\
\hline Any minor event & 100 & 33.90 & 109 & 36.95 & 101 & 34.24 & 113 & 38.31 & 100 & 30.77 & 108 & 33.23 & 106 & 32.62 & 114 & 35.08 \\
\hline $\begin{array}{c}\text { Air leak and other } \\
\text { pneumothorax }\end{array}$ & 70 & 23.73 & 75 & 25.42 & 65 & 22.03 & 70 & 23.73 & 78 & 24 & 80 & 24.62 & 78 & 24 & 81 & 24.92 \\
\hline $\begin{array}{l}\text { Atelectasis/pulmonary } \\
\text { collapse }\end{array}$ & 30 & 10.17 & 33 & 11.19 & 36 & 12.2 & 43 & 14.58 & 19 & 5.85 & 25 & 7.69 & 24 & 7.38 & 28 & 8.62 \\
\hline Cellulitis & 0 & 0 & 1 & 0.34 & 0 & 0 & 0 & 0 & 0 & 0 & 0 & 0 & 0 & 0 & 1 & 0.31 \\
\hline Chylothorax & 1 & 0.34 & 1 & 0.34 & 3 & 1.02 & 3 & 1.02 & & & & & & & & \\
\hline $\begin{array}{l}\text { Spontaneous tension } \\
\text { pneumothorax }\end{array}$ & 0 & 0 & 0 & 0 & 1 & 0.34 & 2 & 0.68 & 3 & 0.92 & 3 & 0.92 & 4 & 1.23 & 4 & 1.23 \\
\hline
\end{tabular}

RATS, Robot-assisted thoracic surgery; VATS, video-assisted thoracic surgery; $S D$, standard deviation.

versus VATS lobectomy $(\$ 30,365$ vs $\$ 20,238)$ and RATS wedge resection versus VATS wedge resection $(\$ 27,969$ vs $\$ 17,887)$. Regarding adverse events, results were confirmatory for major events in both lobectomy and wedge resection with no statistical differences. Regarding minor events, there were no differences for patients undergoing wedge resection. However, there was a significant difference for lobectomies. Patients who underwent lobectomy with the robot were 4.24 (odds ratio) times more likely to have a minor event then their nonrobotic counterparts $(P<.0001)$.

\section{DISCUSSION}

Based on our matched cohorts, there seems to be no differences between robot-assisted lobectomy and wedge resection procedures when considering intraoperative and postoperative complications. After matching and creating 2 balanced cohorts, robot-assisted procedures were associated with higher hospital costs, with an average incremental cost per procedure of $\$ 4565$ for lobectomy and $\$ 2992$ for wedge resection. Robot-assisted wedge procedures were also associated with longer operating room times.
The findings related to higher hospital costs associated with robotic surgery are consistent with similar studies in the literature evaluating minimally invasive surgical procedures $^{15,16}$; robotic surgery is consistently more expensive.

Another important consideration is that the costs associated with robotic surgery in these studies do not account for substantial acquisition costs for the robot. The robotic unit costs between $\$ 1$ million and $\$ 2.5$ million, and is associated with annual maintenance costs of $\$ 100,000$ to $\$ 180,000 .{ }^{17}$ The combination of limited high-quality clinical evidence comparing traditional VATS and RATS lobectomy and wedge resection to date and relatively high costs raises questions about the cost-effectiveness of this technology. In addition, robotic surgery ideally requires a dedicated operating team and an additional surgeon at the table, who are not generally required for standard VATS procedures. This cost is difficult to assess but certainly needs to be considered.

Important strengths of this analysis included the prospectively developed protocol that directed the analysis, the quasi-randomization propensity scoring methodology that

TABLE 7. Adverse events after matching

\begin{tabular}{|c|c|c|c|c|c|c|c|c|}
\hline & \multicolumn{4}{|c|}{ Lobectomy } & \multicolumn{4}{|c|}{ Wedge resection } \\
\hline & Odds ratio estimate & Lower CI & Upper CI & $P$ value & Odds ratio estimate & Lower CI & Upper CI & $P$ value \\
\hline \multicolumn{9}{|c|}{ Original hospital stay or within $30 \mathrm{~d}$ of follow-up } \\
\hline Major & 0.864 & 0.537 & 1.389 & .5458 & 1.24 & 0.807 & 1.905 & .3265 \\
\hline Minor & 1.015 & 0.722 & 1.427 & .9308 & 0.971 & 0.695 & 1.357 & .8647 \\
\hline \multicolumn{9}{|c|}{ Original hospital stay only } \\
\hline Major & 0.789 & 0.473 & 1.316 & .3645 & 1.224 & 0.763 & 1.963 & .4013 \\
\hline Minor & 1.032 & 0.728 & 1.462 & .8589 & 0.927 & 0.659 & 1.304 & 6639 \\
\hline
\end{tabular}

CI, Confidence interval. 
was used, the broad geographic and demographic representation of US hospitals included in the sample, and the fact that these data are relatively recent and represent a national setting. This study also had some noteworthy limitations. Because the data were mined from a hospital administrative database used for billing purposes, certain data points could not be captured or could not be clearly identified. Examples include patient body mass index and patient behavior such as smoking habits. An analysis of pain scores, quality of life, morbidity, and time to return to work would be interesting contributions to the literature, but these data are not available in the database used in this analysis. This analysis was limited to patients who underwent VATS or RATS procedures only, and excluded those procedures that were converted from RATS to VATS or to open thoracotomy. Furthermore, data regarding the precision of robotic versus nonrobotic procedures, including surgical margins and adequacy of lymph node dissection, could not be evaluated. The dataset provides operating room time and is not suited to further exploration regarding time allotted to set-up, bronchoscopy, take down of adhesions, preresection examination or other subcategories. The analysis was limited to a 30 -day perioperative period, which limits analysis related to long-term survival or potential long-term complications. However, these limitations are inherent to the data source and could be rationalized to affect both cohorts similarly; therefore, the risk of bias in 1 cohort is lessened. The surgeon and institutional learning curve for using robotic technology could not be evaluated. Because robotic lung surgery is a relatively new procedure, there may be future potential efficiencies in both cost and time related to increasing familiarity with this technology.

\section{CONCLUSIONS}

This study represents the most up-to-date and expansive analysis of cost and effectiveness outcomes associated with RATS and VATS procedures in a national setting. These findings reveal little clinical differences in perioperative adverse events. Coupled with the increased cost of the robot per case and increased operative times for robotic lobectomy and wedge resections, results suggest that further consideration is warranted before using this technology when standard VATS seems to provide better results. Future studies that evaluate cost relative to robotic-assisted case volume and prospective randomized controlled studies focusing on comparative effectiveness between traditional and robotic-assisted thoracic procedures are needed.

\section{References}

1. Barker A, Maratos EC, Edmonds L, Lim E. Recurrence rates of video-assisted thoracoscopic versus open surgery in the prevention of recurrent pneumothoraces: a systematic review of randomised and non-randomised trials. Lancet. 2007;370:329-35.

2. Cheng D, Downey RJ, Kernstine K, Stanbridge R, Shennib H, Wolf R, et al. Video-assisted thoracic surgery in lung cancer resection: a meta-analysis and systematic review of controlled trials. Innovations (Phila). 2007;2:261-92.

3. Sedrakyan A, van der Meulen J, Lewsey J, Treasure T. Video assisted thoracic surgery for treatment of pneumothorax and lung resections: systematic review of randomised clinical trials. BMJ. 2004;329:1008.

4. Whitson BA, Groth SS, Duval SJ, Swanson SJ, Maddaus MA. Surgery for early-stage non-small cell lung cancer: a systematic review of the videoassisted thoracoscopic surgery versus thoracotomy approaches to lobectomy. Ann Thorac Surg. 2008;86:2008-16; discussion 16-18.

5. Flores RM, Alam N. Video-assisted thoracic surgery lobectomy (VATS), open thoracotomy, and the robot for lung cancer. Ann Thorac Surg. 2008;85:S710-5.

6. McKenna RJ Jr, Houck W, Fuller CB. Video-assisted thoracic surgery lobectomy: experience with 1,100 cases. Ann Thorac Surg. 2006;81:421-5; discussion 5-6.

7. Cao C, Manganas C, Ang SC, Peeceeyen S, Yan TD. Video-assisted thoracic surgery versus open thoracotomy for non-small cell lung cancer: a meta-analysis of propensity score-matched patients. Interact Cardiovasc Thorac Surg. 2013;16: 244-9.

8. Cajipe MD, Chu D, Bakaeen FG, Casal RF, LeMaire SA, Coselli JS, et al. Videoassisted thoracoscopic lobectomy is associated with better perioperative outcomes than open lobectomy in a veteran population. Am J Surg. 2012;204: $607-12$.

9. Deutsch GB, Sathyanarayana SA, Gunabushanam V, Mishra N, Rubach E, Zemon H, et al. Robotic vs. laparoscopic colorectal surgery: an institutional experience. Surg Endosc. 2012;26:956-63.

10. Masterson TA, Cheng L, Boris RS, Koch MO. Open vs. robotic-assisted radical prostatectomy: a single surgeon and pathologist comparison of pathologic and oncologic outcomes. Urol Oncol. 2013;31:1043-8.

11. Turchetti G, Palla I, Pierotti F, Cuschieri A. Economic evaluation of da Vinciassisted robotic surgery: a systematic review. Surg Endosc. 2012;26:598-606.

12. Premier, Inc. Available from: http://www.premierinc.com/. Accessed January 12, 2012.

13. Averill RF, Goldfield N, Hughes JS, Bonazelli J, McCullough EC, Steinbeck BA, et al. What are APR-DRGs? An introduction to severity of illness and risk of mortality adjustment methodology. White paper. 2003 Available from: http:// solutions.3m.com/3MContentRetrievalAPI/BlobServlet?locale=it_IT\&lmd=12 $18718280000 \&$ assetId $=1180603360910 \&$ assetType $=$ MMM_Image\&blobAttri bute=ImageFile. Accessed January 12, 2012.

14. Mayo Clinic. Gmatch macro developed by Erik Bergstralh and Jon Kosanke. 2003. Available from: http://www.mayo.edu/research/departments-divisions/ department-health-sciences-research/division-biomedical-statistics-informatics/ software/locally-written-sas-macros. Accessed November 20, 2011.

15. Weissman JS, Zinner M. Comparative effectiveness research on robotic surgery. JAMA. 2013;309:721-2.

16. Wright JD, Ananth CV, Lewin SN, Burke WM, Lu YS, Neugut AI, et al. Robotically assisted vs laparoscopic hysterectomy among women with benign gynecologic disease. JAMA. 2013;309:689-98.

17. Intuitive Surgical Investor Presentation Q4 2009. Available from: http://investor. intuitivesurgical.com/phoenix.zhtml?c=122359\&p=irol-IRHome. Accessed January $12,2012$. 
APPENDIX TABLE 1. Comorbid conditions

\begin{tabular}{lc}
\hline \multicolumn{1}{c}{ Condition } & ICD-9 code \\
\hline Myocardial infarction, & $410 . \mathrm{xx}, 412$ \\
$\quad$ acute or old & 428.0 \\
Congestive heart failure & $428.20,428.22,428.30$, \\
Other chronic or unspecified & $428.32,428.40,428.42,428.9$ \\
$\quad$ heart failure & $440 . \mathrm{xx}, 443.8 \mathrm{x}, 443.9$ \\
Peripheral vascular disease & $290 . \mathrm{xx}, 294 . \mathrm{xx}, 331.0,331.11$, \\
Dementia & $331.19,331.2,331.7,331.82$ \\
& $490 . \mathrm{xx}-494 . \mathrm{xx}, 495 . \mathrm{x}, 496,500-505$ \\
Chronic pulmonary disease & $710 . \mathrm{xx}, 714 . \mathrm{xx}$ \\
Connective tissue disease & $571 . \mathrm{x}, 572 . \mathrm{x}, 573 . \mathrm{xx}$ \\
Liver disease & $070.22-070.23,070.32-070.33$, \\
Chronic viral hepatitis & $070.44,070.54$ \\
& $585 . \mathrm{xx}$ \\
Renal insufficiency, chronic & $249 . \mathrm{xx}, 250 . \mathrm{xx}$ \\
Diabetes mellitus & $342 . \mathrm{xx}$ \\
Hemiplegia & $343.1,343.4$ \\
Due to cerebral palsy & $438.2 \mathrm{x}$ \\
Due to previous & \\
$\quad$ cardiovascular accident &
\end{tabular}

ICD, International Classification of Diseases.

APPENDIX TABLE 2. Postoperative procedure-specific complications

\begin{tabular}{llc}
\hline Category & \multicolumn{1}{c}{ Pulmonary } & ICD-9 code \\
\hline Major & Acute respiratory failure & $518.81,518.84,518.5$ \\
Major & Empyema & 510.9 \\
Major & Bronchopleural fistula & 510.0 \\
Major & Pneumonia & $480 . x$ to $486,507.0$ \\
Minor & Spontaneous tension & 512.0 \\
& $\quad$ pneumothorax \\
Minor & Atelectasis/pulmonary & 518.0 \\
& $\quad$ collapse & \\
Minor & Air leak and other & $512.1,512.8$ \\
& pneumothorax & \\
Minor & Chylothorax & 457.8 \\
Minor & Cellulitis & 682.2 \\
\hline
\end{tabular}

ICD, International Classification of Diseases. 